\title{
A influência dos processos neuropsicológicos no aprendizado da leitura em crianças com dislexia
}

\author{
The influence of neuropsychological processes in children with dyslexia that are learning to read \\ La influencia de los procesos neuropsicológicos en el aprendizaje de la lectura en niños con dislexia
}

Recebido: 22/05/2021 | Revisado: 29/05/2021 | Aceito: 04/06/2021 | Publicado: 18/06/2021

\author{
Beatriz Costa Campos \\ ORCID: https://orcid.org/0000-0001-6155-761X \\ Centro Universitário Una, Brasil \\ E-mail: beatrizcamps98@gmail.com \\ Gabriel Santos Vieira \\ ORCID: https://orcid.org/0000-0003-2722-690X \\ Centro Universitário Una, Brasil \\ E-mail: psigabrielvieira@gmail.com \\ Leidianny Kelly da Costa \\ ORCID: https://orcid.org/0000-0001-5756-3566 \\ Centro Universitário Una, Brasil \\ E-mail: leidiannykelly@ hotmail.com \\ Rosemary Pereira Costa e Barbosa \\ ORCID: https://orcid.org/0000-0001-5368-2162 \\ Instituto Federal de Educação, Ciência e Tecnologia de Minas Gerais, Brasil \\ E-mail: rose.costa@ifmg.edu.br
}

\begin{abstract}
Resumo
O objetivo deste artigo é descrever a influência dos processos neuropsicológicos influenciam no aprendizado da leitura de crianças com dislexia, a partir de uma revisão bibliográfica sobre o tema. Nesse percurso, são examinadas diversas influências socioambientais relacionadas às dificuldades específicas de aprendizagem de leitura, como o sistema de ensino e o contexto sociofamiliar. $O$ trabalho contribui academicamente com a compreensão do transtorno, mostrando como os aspectos biológicos, cognitivos e sociais interferem no processo da dislexia e enfatizando como uma intervenção bem-sucedida depende de uma avaliação criteriosa e multidimensional desses fatores relacionados às dislexias de desenvolvimento.
\end{abstract}

Palavras-chave: Dislexia; Neuropsicologia; Crianças; Processamento fonológico; Aprendizagem.

\section{Keywords}

The objective of the article is to describe how the processes of this neuropsychological influence the learning of reading of children with dyslexia, from a literature review on the subject. Along this path, various socioenvironmental influences related to specific difficulties in learning to read are examined, such as the education system and the social-family context. Thus, the work contributes academically to the understanding of the disorder, showing how biological, cognitive and social aspects interfere in the dyslexia process and emphasizing how a successful intervention depends on a careful and multidimensional evaluation of these factors related to developmental dyslexias.

Abstract: Dyslexia; Neuropsychology; Children; Phonological processing; Learning.

\section{Resumen}

El objetivo de este artículo es describir la influencia de los procesos neuropsicológicos que influyen en el aprendizaje a leer de los niños con dislexia, a partir de una revisión bibliográfica sobre el tema. En este camino se examinan diversas influencias socio ambientales relacionadas con las dificultades específicas de aprendizaje en lectura, como el sistema educativo y el contexto socio-familiar. El trabajo contribuye académicamente a la comprensión del trastorno, mostrando cómo los aspectos biológicos, cognitivos y sociales interfieren en el proceso de la dislexia y enfatizando cómo una intervención exitosa depende de una evaluación cuidadosa y multidimensional de estos factores relacionados con las dislexias del desarrollo.

Palabras clave: Dislexia; Neuropsicología; Niños; Procesamiento fonológico; Aprendiendo.

\section{Introdução}

O presente artigo visa compreender como os processos neuropsicológicos influenciam no aprendizado da leitura de crianças com dislexia. De acordo com a Associação Brasileira de Dislexia (ABD, 2016), a dislexia é um transtorno específico 
de aprendizagem, de origem neurobiológica, que pode acometer pessoas de todas as origens e níveis intelectuais, e que se caracteriza por dificuldade na precisão e/ou fluência no reconhecimento de palavras e baixa capacidade de decodificação e de soletração. Essas dificuldades são resultado de déficits no processamento fonológico, que normalmente está abaixo do que é esperado em relação a outras habilidades cognitivas. Como consequência, são comuns os problemas na compreensão e, com isso, a redução da experiência de leitura.

Segundo Rizzutti e Muskat (2012, p. 14), a dislexia provoca alterações no desenvolvimento da escrita e leitura, em conjunto com dificuldades em decodificação ou soletração, de modo que o indivíduo pode apresentar uma inteligência normal sem características visíveis e claras de alterações psíquicas.

As causas exatas da dislexia ainda não estão completamente claras, porém, alguns estudos com neuroimagem constataram diferenças no desenvolvimento e funcionamento do hemisfério esquerdo do cérebro (Moysés; Collares, 2011). Além disso, os estudos mostram um forte indicativo de componente genético, uma vez que os estudos clínicos apontam que mais de $50 \%$ das crianças com dislexia têm pessoas na família com o mesmo transtorno. Entretanto, de acordo com Massi e Santana (2011), mesmo com a presença de estudos que concluem déficits de processamento visual e auditivo como causa explicativa para a dislexia, o modelo do déficit fonológico é comumente o mais aceito atualmente.

Dessa forma, procurando responder à questão levantada, este trabalho apresenta como objetivo geral investigar como os fatores sociais e biológicos se correlacionam no processo de aquisição de conhecimento, especificamente, de crianças disléxicas. E ainda, como objetivos específicos, ele visa descrever o processo de aprendizagem de uma criança com dislexia segundo a perspectiva da neuropsicologia, relacionar os aspectos neuropsicológicos aos psicossociais no processo de aprendizagem e compreender como a neuropsicologia pode auxiliar o processo de aprendizagem de crianças disléxicas.

\section{Metodologia}

Neste trabalho, utilizou-se a metodologia de revisão bibliográfica sistemática, a partir de análise de textos acadêmicos sobre dislexia e neuropsicologia. A revisão bibliográfica sistemática segundo Galvão e Ricarte (2019), segue um protocolo formulado anteriormente onde se busca responder a questões específicas a partir do estudo de um corpo teórico de documentos, delimitados por banco de dados, descritores e determinado período de tempo. Sua lógica busca resguardar a reprodutividade da mesma por outros pesquisadores Portanto, foram realizadas buscas por artigos em repositórios científicos, como: SciELO, PePSIC, BIREME, REAC e RSD utilizando a combinação dos seguintes descritores: "dislexia" e "neuropsicologia". Como critérios de inclusão, optou-se por artigos redigidos em língua portuguesa que remetiam à temática abordada, referentes aos anos de 1993 a 2020. Como critérios de exclusão, não foram considerados na revisão artigos em língua estrangeira e textos duplicados.

A busca realizada a partir dos descritores supracitados retornou 38 artigos, dos quais 12 eram duplicados, 3 estavam em língua espanhola e 7 não se relacionavam à temática do presente artigo. Portanto, a partir dos critérios de inclusão e exclusão especificados, 16 artigos são analisados no presente trabalho.

Os artigos analisados são apresentados no Quadro 1: 
Quadro 1 - Artigos analisados.

\begin{tabular}{|c|c|c|}
\hline Autor & Ano de Publicaçào & Titulos dos Artigos \\
\hline Kajuhara, O.T. & 1997 & $\begin{array}{l}\text { Avaliaçio das babihdades fonologicas } \\
\text { de disléxicos do decenwolvimento }\end{array}$ \\
\hline $\begin{array}{l}\text { Salles, J.F.; Pareste, M.A. M. P.; } \\
\text { Machado, S.S. }\end{array}$ & 2004 & $\begin{array}{l}\text { As dislexias de desenvolvimento: } \\
\text { aspectos neuropticológicos e cormitivos }\end{array}$ \\
\hline Salles, J. F. \& Parente, M. A. M. P. & 2006 & $\begin{array}{l}\text { Funçòes neturopsicologicas em crianças } \\
\text { com dificuldades de leitura e escrita. }\end{array}$ \\
\hline Salles, J. F. \& Parente, M. A. M. P. & 2006 & $\begin{array}{l}\text { Heterozeneidsde nas estratégias de } \\
\text { leitura/escrith em crianças com } \\
\text { dificuldades de leitura e escnta. }\end{array}$ \\
\hline Capovalla, A. G.S. & 2007 & $\begin{array}{l}\text { Contribuiçōes da neuropsicologia } \\
\text { cognitiva e da avaliaçăo } \\
\text { neuropsicológica a compreensio do } \\
\text { funcionamento cognitivo humano. }\end{array}$ \\
\hline Rubino, $\mathbb{R}$. & 2008 & $\begin{array}{l}\text { Sobre o conceito de dislexia e seus } \\
\text { efeatos no discurzo zocial }\end{array}$ \\
\hline Salles, J. F. \& Parente, M. A. M. P. & 2008 & $\begin{array}{l}\text { Variabilidade no deseapenbo em } \\
\text { tarefas neruropsicológicas entre criancas } \\
\text { de } 2^{*} \text { série com dificuldades de leitura e } \\
\text { eacrita. }\end{array}$ \\
\hline $\begin{array}{c}\text { Collares, C.A. \& Moysès, } \\
\text { M.A.A. }\end{array}$ & 2010 & $\begin{array}{l}\text { Preconceitos no coticiano escolar: a } \\
\text { medicalizaçảo do processo ensino- } \\
\text { aprendizagem. }\end{array}$ \\
\hline Massi, G. \& Santana, A. P. O. & 2011 & $\begin{array}{l}\text { A desconstruçio do conceito de } \\
\text { dislexia: conflito entre verdades. }\end{array}$ \\
\hline Alves, R.J. R. et al & 2015 & $\begin{array}{l}\text { Teste para Idestificaçào de Sinais de } \\
\text { Dislexia: processo de construçio }\end{array}$ \\
\hline Simpor, $\mathbb{R}$ & 2015 & Dislexcis: uma anälise histónca e social \\
\hline Sousa, A. M. O. P. \& Alvez, R. R. N. & 2017 & $\begin{array}{l}\text { A neurociéncia na formaçio dos } \\
\text { educadores e sua contnbuiçầo no } \\
\text { processo de sprendizagem. }\end{array}$ \\
\hline $\begin{array}{c}\text { Medina, G. B. K. ; Sorza, F. F } \\
\text { Gumaraes, S. R. K. }\end{array}$ & 2018 & $\begin{array}{l}\text { Funçóes executrivas e leitura etm } \\
\text { crianças brasileinas com dislexia do } \\
\text { desenvolvimento. }\end{array}$ \\
\hline Silva, RM & 2018 & Dislexia na Aprendizagem. \\
\hline Goncalves, M. A.F. & 2019 & A dislexia no ensino fundamental. \\
\hline Lima, N, R. F, et al & 2020 & $\begin{array}{c}\text { Dislexia: a umportincia do diagnostico } \\
\text { para uma intervençio precisa. }\end{array}$ \\
\hline
\end{tabular}

Fonte: Autores (2021).

As análises dos textos acadêmicos selecionados sobre dislexia e neuropsicologia são apresentadas a seguir.

\section{Resultados e Discussões}

\subsection{Panorama da Dislexia na história e seu contexto social}

Segundo Muszkat e Rizzutti (2012), a escrita surgiu ao longo da história de forma morosa, a partir do desenvolvimento evolutivo da cognição humana. Inicialmente, a escrita era pictórica, realizada a partir de símbolos e figuras que modificaram com o passar do tempo. A intenção das imagens era transmitir mensagens para qualquer outro indivíduo ou grupo. A partir da criação do alfabeto deu-se início com os fenícios, sendo posteriormente conduzida com os romanos para o atual o qual conhecemos que foram se modificando com o passar do tempo e atingindo a complexidade atual da escrita e leitura, consequentemente o processo de alfabetização foi sendo construindo ao longo dos séculos.

Segundo Blasi (2006) dislexia pode ser descrita nas literaturas como uma dificuldade apresentada durante o processo de aprendizagem da leitura e da escrita, sendo uma dificuldade específica onde o indivíduo possui dificuldade para reconhecer, ordenar e associar os sons e as letras, de forma a qual não há comprometimento intelectual, auditivo ou visual. Independente se 
a pessoa está motivada, possuí o processo de escolarização considerado adequado e está inserida em um ambiente sociocultural favorável, ainda sim as dificuldades da pessoa com dislexia persistem.

Tais fatores mencionados anteriormente, como reconhecer, associar e ordenar os sons e as letras acabam dificultando o entendimento da ortografia e:

[...] a razão principal de fracasso parece ser a dificuldade apresentada por certas crianças, mesmo em línguas com ortografia quase inteiramente regular, na descoberta do fonema, chave para a compreensão do princípio alfabético da escrita (Morais, 1995 apud Muszkat, Rizzutti, 2012, p. 20).

Deste modo, tais dificuldades da leitura e da escrita é o que atualmente te chamamos de dislexia. Segundo Ianhez e Nico (2002):

Ao desmembrarmos a palavra, de imediato temos a primeira noção básica do que vem a ser a dislexia. DIS = distúrbio; dificuldade; LEXIA = leitura (do latim) e/ou linguagem (do grego); DISLEXIA = distúrbio de linguagem. (IANHEZ; NICO, 2002, p.25).

Citando pela primeira o termo "cegueira verbal", em 1896, o Dr. W. Pringle Morgan publicou um estudo que relatava um caso de um adolescente que, com inteligência igual ou superior a seus colegas, afirmava que as letras e as palavras escritas em conjunto não possuíam significado para ele. A partir disso, Morgan observou básicos elementos que atualmente são primordiais para a caracterização da dislexia. Os primeiros indícios de distúrbios de leitura acontecem em 1896 quando o médico inglês W. Pingle Morgan descreve,

[...] um jovem brilhante de quatorze anos, rápido em jogos, mas que tinha grande dificuldade para aprender a ler, cujos professores achavam que poderia ser o melhor aluno da classe se toda a instrução fosse dada oralmente. (Pingle apud Santos; Navas, 2002, p. 28).

Segundo Ribeiro (2013), esse relato foi de extrema importância, por sua contribuição na descrição clínica da dificuldade adquirida da leitura, na ausência de problemas oftalmológicos ou de acuidade visual, algo que permitiu que, posteriormente, Morgan relatasse o primeiro caso de dislexia. A facilidade a qual o paciente apresentava em relação à leitura dos números bem como à resolução de exercícios de operações numéricas despertou o interesse de Morgan, que concluiu que Percy apresentava uma "cegueira verbal", a expressão em questão que já estava sendo utilizada por alguns neurologistas a fim de nomear os casos em os quais os pacientes adultos, com boa visão e inteligência considerada normal, perdiam a capacidade de ler após sofrerem algum tipo de lesão cerebral.

O relato mais antigo de "cegueira verbal" foi descrito em 1676, pelo Dr. Johann Schmidt, referindo-se a um homem de 65 anos que perdeu a capacidade de ler após um derrame. Embora pudesse ver todas as letras com nitidez, independentemente do tamanho, os caracteres não tinham significado. É essencial salientarmos que a história da conceitualização da dislexia baseiase pela sua suposta proximidade com os fenômenos afásicos, conforme mencionado por Rubino (2008):

Quando os neurologistas tomaram consciência, em princípios deste século [século XX], da anomalia que consistia na impossibilidade, para uma criança normal, de ler e adquirir a organização da linguagem, pensaram descobrir com isto uma entidade mórbida próxima à alexia ou ao agramatismo descrito no adulto no momento da afasia. O qualificativo de cegueira verbal congênita dá testemunho desta concepção, do mesmo modo que as múltiplas denominações propostas nesta época (Rubino apud Launay, 1984, p. 15).

Em 1900, o oftalmologista escocês James Hinshelwood, descreve a existência de uma cegueira verbal congênita. Diferente da "cegueira verbal" adquirida, a congênita apresentava evolução á medida que as exigências escolares aumentavam, 
ou seja, os sinais não eram notads de forma imediata a partir de um determinado evento e de forma a não afetar a capacidade muscular do paciente.

Ao avaliarmos a questão histórica ligada à dislexia, notamos diferentes concepções sobre o tema, como as ligadas a fatores errôneos como de "Leitura Fraca". Muskat e Rizzutti (2012) se referem à origem da palavra dislexia: dys indicam que significa uma disfunção, ou seja, um funcionamento anormal ou prejudicado, enquanto lexia remete à linguagem em um sentido amplo da palavra.

Conforme relatado por Signor (2015), os principais sintomas da dislexia eram frequentemente negligenciados, sendo erroneamente classificados como deficiência intelectual, problemas oftalmológico, trazendo grandes prejuízos para o indivíduo, geralmente socialmente ridicularizado.

Em relação contexto social, os primeiros sintomas e traços são notados em idade escolar, momento em que a criança começa interagir e a ter contato com as principais dificuldades do transtorno, em razão de ser o espaço em que a leitura e a escrita são frequentemente utilizadas e trabalhadas,

\subsection{Conceituando a Dislexia: Perfil e características em crianças disléxicas com idade escolar}

A leitura e a escrita são atividades complexas que exigem das crianças vários processos cognitivos e linguísticos, exigindo o desenvolvimento da linguagem oral e conhecimentos gramaticais. Quando ocorrem problemas na parte cognitiva relativa à leitura, tem-se o transtorno da dislexia.

De acordo com a Associação Brasileira de Dislexia (ABD, 2016), a dislexia é um transtorno específico de aprendizagem, e pode atingir pessoas de todas as origens e níveis intelectuais. De condição neurobiológica, muitas vezes herdada, a dislexia é caracterizada por dificuldades na aquisição e desenvolvimento das habilidades de leitura e escrita maiores do que se esperaria considerando o nível intelectual da pessoa. Em geral, na fase pré-escola as crianças já apresentam sinais do transtorno, como dispersão, atraso do desenvolvimento da fala e da linguagem, dificuldades de aprender rimas e canções e o fraco desenvolvimento da coordenação motora.

Segundo o Manual Diagnóstico e Estatístico de Transtornos Mentais - DSM-5(APA, 2014), a dislexia é denominada um de transtornos do neurodesenvolvimento, sendo um transtorno específico de aprendizagem. Para identificação do transtorno, o sujeito deve apresentar pelo menos um dos seguintes sintomas: (1) leitura lenta e imprecisa, com grande esforço e desconforto; muitas vezes, o sujeito tenta adivinhar as palavras e tem dificuldade de soletrá-las; (2) dificuldade na compreensão da leitura ou grande dificuldade de compreender o sentido daquilo que é lido; (3) na ortografia, ocorrência de adição, omissão ou substituição das palavras; (4) dificuldade na escrita, com diversos erros de gramática ou pontuação, além de organização inadequada de parágrafos. Além disso, é muito comum erros na leitura e escrita de origem fonológica e desenvolvimento tardio da linguagem oral.

Portanto, para a identificação do transtorno, o melhor a ser feito é uma avaliação especializada, a partir de testes padronizados, verificando o desempenho do sujeito em relação ao seu nível de inteligência e aquilo que é esperado para a sua idade cronológica e inteligência.

Segundo Silva (2018), a dislexia não consiste simplesmente em um processo de aprendizado ruim ou uma baixa inteligência, mas trata-se de uma condição hereditária com alterações genéticas, apresentando ainda alterações no padrão neurológico, o que implica em problemas com a organização espacial, organização temporal, atraso de linguagem e problemas de ordem afetiva. No entanto, o autor também destaca que a dislexia é uma perturbação ou transtorno ao nível de leitura, escrita e soletração que, muitas vezes, leva ao fracasso escolar de muitas crianças. Em direção semelhante, Moysés e Collares (2011) destacam que os primeiros sinais de dislexia podem ser vistos ainda quando criança, já que o aluno tem grande dificuldade em assimilar o que é passado pelo professor. De acordo com Pimenta (2012) apud Gonçalves (2019), por não ter a mesma facilidade 
em assimilar um texto, como seus colegas, a criança disléxica pode se sentir desmotivada e perder o interesse em aprender. No entanto, para a maioria dos educadores a dislexia é considerada como fruto de uma má alfabetização, o que acaba gerando uma descriminação que, consequentemente, impossibilita ações da escola para a superação desse problema. Desse modo, a melhor forma de intervir nessa situação e ter profissionais qualificados para avaliar se é a dislexia, pois a dislexia não é o único distúrbio que inibe o aprendizado, mas é o mais comum.

Mesmos com diversas teorias que falam em déficits visuais e auditivos, o mais aceito atualmente entre os pesquisadores é a hipótese do déficit fonológico. Moysés e Collares (2011), por exemplo, consideram que os problemas iniciais da leitura são decorrentes de dificuldades no processamento fonológico. O processamento fonológico é a habilidade que o sujeito tem de analisar a fala oral, identificando palavras individuais, parte de palavras e sílaba, até o menor componente de som (fonemas). Sendo que a velocidade e a capacidade de armazenar, manipular e resgatar os componentes sonoros da palavra também fazem parte do processamento fonológico. Pesquisas que utilizam instrumentos de neuroimagem mostram, em testes que requerem processamento fonológico, ativação cerebral diferenciada em indivíduos considerados disléxicos. Segundo Gonçalves e Navarro (2012), citado por Lira et al (2020) como a dislexia é um distúrbio neurológico, ela afeta o processamento e a interpretação de informações. Salles, Parente e Machado (2004) afirmam que, quando estimuladas na parte fonológica, crianças que apresentam dificuldades específicas no aprendizado alcançam resultados bastante efetivos. A intervenção direta em reconhecimento de palavras isoladas, por exemplo, tem se mostrado a mais efetiva para melhorar o processo da leitura.

Portanto, por ser uma disfunção genética caracterizada por falha no processamento da linguagem, esse transtorno é um dos vários distúrbios da aprendizagem que é identificado na idade escolar. Por isso, a escola tem que proporcionar alternativas para oferecer recursos às necessidades especiais dos educandos, desenvolvendo e implementando intervenções que estimulem o desenvolvimento fonológico das crianças menores. Essas alterações funcionais podem ser alteradas por estímulo ambiental ou por meio de intervenções terapêuticas. Salles e Parente (2006), por exemplo, consideram que o mais importante do que afirmar se uma criança é ou não disléxica, é analisar o contexto no qual ela está inserida e planejar as suas estratégias para melhorar o processo ensino- aprendizagem dessa criança.

Apesar de ser algo que não ofereça riscos biológicos à saúde desse indivíduo, os transtornos de aprendizagem, se não tratados, podem trazer uma série de prejuízos sociais como: sentimento de incapacidade, baixa autoestima, sentimento de não pertencimento ao seu grupo social, dificuldades no exercício de suas funções sociais, isolamento e exclusão social, dentre outros. Salles, Parente e Machado (2004) afirmam que o processo de avaliação e diagnóstico das dificuldades específicas de leitura deve ser realizado por equipe interdisciplinar, envolvendo diversas especialidades como neurologia, fonoaudiologia, psicologia, pedagogia ou psicopedagogia, além de considerar a percepção do professor que acompanha o processo de aprendizagem da criança. Em relação a intervenção nos quadros de dificuldades de leitura, também se faz necessária uma abordagem multidisciplinar que desenvolva um trabalho específico e adequado a cada indivíduo.

\subsection{A influência dos processos neuropsicológicos no aprendizado de crianças com dislexia}

A neuropsicologia é um campo das neurociências que estuda o processo de organização cerebral, estabelecendo conexões entre os âmbitos cognitivo e comportamental e o funcionamento do Sistema Nervoso Central (SNC). No campo da Psicologia, a neurociência apresenta diversas contribuições através de exames médicos e testes psicológicos, os quais proporcionam um entendimento sobre as funções e alterações do cérebro, determinando se o problema apresentado é de origem biológica ou psicológica. Além das contribuições para o campo da Psicologia, a Neurociência também auxilia a Pedagogia. As dificuldades de leitura e escrita em crianças são tema de interesse multidisciplinar, nos meios educacionais, acadêmicos e clínicos (Salles \& Parente, 2006, p. 153). Como relata Salles e Parente (2008), o desenvolvimento dos processos de leitura e escrita na 
criança depende de uma série de fatores, os quais estão relacionados não somente ao desenvolvimento de habilidades neuropsicológicas, mas também a fatores biológicos/maturacionais e psicossociais (familiares e escolares).

Por meio dela é possível compreender fatores que influenciam no processo de aprendizagem, tais como os comportamentos, os estímulos e a maneira como o cérebro se comporta.

De acordo com Cosenza e Guerra (2011) apud Sousa e Alves (2017):

Sabe-se que os estados mentais são provenientes de padrões de atividade neural, então, a aprendizagem é alcançada por meio da estimulação das conexões neurais, que podem ser fortalecidas dependendo da qualidade da intervenção pedagógica (Cosenza; Guerra, 2011 apud Sousa e Alves, 2017, p. 321).

O cérebro passa por processos de reorganização constantemente. Um desses processos é a "poda neural”, onde o cérebro planeja a morte celular de vários neurônios não muito utilizados, abrindo espaço para os mais utilizados e para os novos neurônios (neuroplasticidade). Durante a vida, o cérebro passa por diversas podas, mas as principais ocorrem na primeira infância (6/7 anos) e na adolescência (15/16 anos). A primeira poda é de extrema importância, pois nos primeiros anos de vida a produção de neurônios (sinapses) ocorre em grande escala, uma vez que o cérebro ainda não tem conhecimento sobre a rotina de vida e costumes do indivíduo. À medida que essa criança vai crescendo e se desenvolvendo, o cérebro começa a reconhecer as sinapses mais utilizadas. Em seguida, ocorre a segunda poda neural, mantendo ou descartando esses neurônios. Essa poda é muito benéfica para o cérebro porque através dela ele não produz sinapses desnecessárias e está constantemente abrindo espaço para novas (Neto, 2007).

Conforme afirmam Souza e Alves (2017), a noção de que o cérebro está em constante transformação surgiu nas últimas décadas, pois o entendimento que se tinha sobre ele era o de que, depois de formado, ele não poderia mais ser modificado. Tais descobertas trazem implicações para o processo de ensino-aprendizagem, uma vez que a motivação e a estimulação servirão como facilitadores da aprendizagem. Os estímulos (auditivos, visuais, sensoriais, dentre outros) dados ao aluno pelo professor serão essenciais no seu processo de desenvolvimento. Mas é importante ressaltar que não basta somente estimulá-lo, é necessário que esses estímulos sejam construtivos e positivos, uma vez que irão influenciar no desenvolvimento da memória e da atenção. Assim como o aluno não é um depósito de informações, o professor também não deve ser um reprodutor delas.

De acordo com Fodor (1983), citado por, Capovilla (2007) a Neuropsicologia tem como principal fundamento a independência funcional dos processos neurológicos, ou seja, uma parte do cérebro não executa sua função sozinha. Segundo esse fundamento, se o processo e/ou o desenvolvimento de um componente cognitivo for danificado, isso pode não afetar todo o processo e/ou sistema cognitivo. Portanto, caso ocorra uma lesão ou problema de desenvolvimento em uma determinada região do sistema cognitivo, ocorrerá uma alteração específica do seu funcionamento. Estudos de lesões cerebrais mostram que as partes do cérebro não exercem uma mesma função. É através do entendimento desses estudos e de muitos outros que hoje a Neuropsicologia é capaz de detectar possíveis distúrbios e patologias relacionadas ao desenvolvimento anormal do cérebro. Sousa e Alves (2017) explicam que o cérebro tem uma maneira muito interessante de funcionar, pois, ao mesmo tempo em que executa diversas funções, ele não seria capaz de realizá-las sozinho. É como se ele fosse uma orquestra, onde todos os componentes exercessem funções específicas que influenciarão no resultado final.

De acordo com a Associação Internacional de Dislexia (IDA, 2020) na Neuropsicologia a dislexia possui diversas ramificações de conceito (fonológica, visual e mista). Uma delas é a "dislexia fonológica", caracterizada como uma dificuldade grave no processamento fonológico, que resulta em um desempenho insatisfatório na leitura de estímulos desconhecidos. Kajihara (1997) concluiu em seus estudos que a dificuldade de leitura das crianças disléxicas ocorre devido ao déficit fonológico. Em pesquisas realizadas por Alves et al. (2015), crianças com dislexia apresentaram baixo desempenho em testes com estímulos verbais (letras e dígitos), devido ao déficit fonológico. Outra função afetada na dislexia é a flexibilidade cognitiva. De acordo 
com Medina, Souza e Guimarães (2018), essa flexibilidade consiste em pensar além do óbvio, mudar a atenção de uma circunstância para outra, ler algo e ao mesmo tempo compreender significado disso. Outras dificuldades presentes envolvem a memória de curto prazo fonológica e consciência fonológica (Salles; Parente; Machado, 2004). Um estudo realizado por Galaburda e Kemper (1979), citado por Salles, Parente e Machado (2004), avaliou as células cerebrais de disléxicos post-mortem. Durante a análise, foram encontradas deformidades nas células da região do lobo temporal, responsáveis pelo gerenciamento da memória.

Muitos desses estudos são considerados inconclusivos, devido ao tamanho reduzido das amostras, o que dificulta a generalização dos resultados, porque não representam a diversidade de pessoas disléxicas. Apesar disso, eles servem como modelo, neurofuncional e neuroanatômico para entender as dificuldades apresentadas por indivíduos no processo de aprendizagem.

Sousa e Alves (2017) afirmam que para aprender são necessárias as presenças de duas ferramentas principais: a atenção e a memória. Ferramentas que de acordo com a Associação Internacional de Dislexia (IDA, 2020) sofrem alterações em crianças disléxicas, causando: dispersão, falta de atenção, atraso na linguagem e fala, dentre outros. Quando algo novo é apresentado ao cérebro, ele precisa selecionar essas informações e armazenar as mais importantes; essa função é exercida pelos diversos tipos de memória (de curto, médio e longo prazo, dentre outras). A atenção é a seleção de informações, em meio a diversos estímulos, que mais tarde serão selecionados como memórias de curto e longo prazo. Como aponta Sousa e Alves (2017):

[...] o aprendizado e a memória são fases diferentes do mesmo mecanismo progressivo e contínuo. Sem memória, o aprendizado se torna impossível e, sem aprendizado, não existe memória. Aprendizagem, memória e emoção ficam interligadas, quando ativadas pelo processo de aquisição do conhecimento. O desafio para a educação não é apenas saber como ensinar ou como avaliar, mas apresentar o conhecimento em um formato que o cérebro aprenda melhor (Souza e Alves, 2017, p.329).

Os estudos de Fenker e Schütze (2008), citados por Sousa e Alves (2017), demonstram que ao entrar em contato com algo novo e desconhecido, as atividades no hipocampo (estrutura cerebral considerada a principal sede da memória) se potencializam, favorecendo a longa duração da memória e do aprendizado. Isso também é importante para o processo de memorização, uma vez que se sabe que a memória de curto prazo constantemente não consegue absorver tudo o que passa por ela, privilegiando o que considera que deve ser aprendido, já que o cérebro aprende aquilo que considera significativo.

Além da importância da atenção e da memória, vários autores concordam com relação à importância das emoções para o processo de aprendizagem:

A eficácia da aprendizagem é influenciada pelo nosso estado emocional, já que apresentamos tendências para lembrarmos melhor os acontecimentos associados a experiências particularmente felizes, tristes ou angustiantes. Como também nos recordamos melhor dos acontecimentos quando estamos atentos (Morris; Fillenz, 2003 apud Sousa; Alves, 2017, p. 326).

A parte do cérebro responsável pelas emoções é a amígdala. Ela irá regular as emoções, que também são essenciais no processo de aprendizagem. As emoções associadas às motivações podem dificultar ou facilitar o processo de aprendizagem.

Estudos desenvolvidos por Pfromm (1987) e Pintrich e Schunk (2002), citados por Sousa e Alves (2017), demonstram a importância da motivação para que uma ação seja iniciada e sustentada. Após algum tempo, essa motivação não será algo que precisará ser incentivado, pois, irá se tornar um comportamento, uma vez que alunos motivados apresentam maior facilidade em adquirir novos conhecimentos e, por ser algo que irá despertar-lhes o interesse, se tornará algo prazeroso. 
Quando algo é realizado de forma prazerosa ocorre um aumento na qualidade e quantidade das sinapses, proporcionando maiores chances de obter resultados eficazes no processo de aprendizagem. A Neuropsicologia sugere diversas estratégias que podem auxiliar os professores no processo de ensino-aprendizagem. Para que ocorra efetivamente a consolidação do conhecimento é necessário associação de novas sinapses com as já existentes, nutrição adequada do corpo e tempo.

Relacionando fatores biológicos com fatores externo-sociais, ambientais, psíquicos, dentre outros-, a aprendizagem pode ser definida como o processo de interação entre o ambiente e o cérebro, inicialmente provocada por um estímulo físicoquímico e transformando-se, a seguir, em uma sinapse. Após ocorrer essa transformação, essa sinapse será interpretada de diversas formas e sentidos, até a emissão de uma resposta.

Recorrer à Neuropsicologia Infantil se tornou uma consulta essencial nos cuidados da saúde na infância. E quando ocorre um diagnóstico precoce, isso possibilita um trabalho multiprofissional (educadores, psicólogos, neurologistas, fonoaudiólogos, terapeutas ocupacionais, dentre outros), buscando fornecer um tratamento mais eficiente. Só assim, as dificuldades serão compreendidas e adequadamente tratadas.

\section{Conclusão}

Este trabalho teve por objetivo promover uma discussão em torno da influência dos processos neuropsicológicos no aprendizado da leitura de crianças com dislexia, contribuindo academicamente com a compreensão do transtorno, mostrando como os aspectos biológicos, cognitivos e sociais interferem no processo da dislexia.

Os papéis da família e da escola são muito importantes na identificação precoce das dificuldades da criança com dislexia quanto ao tratamento. Considerando que fatores ambientais, como um sistema de ensino que não condiz com as necessidades escolares da criança, influenciam na construção das dificuldades específicas de aprendizagem de leitura, estes contextos também devem ser analisados e ser um componente no processo de intervenção. A orientação aos pais e professores é de extrema importância no programa de intervenção.

De acordo com Capovilla (2007), a neuropsicologia apresenta diversas contribuições, por estabelecer conexões entre os âmbitos cognitivo, comportamental e o funcionamento do SNC, ajudando a compreender fatores que influenciam no processo de aprendizagem, tais como os comportamentos, os estímulos e a maneira como o cérebro se comporta, bem como a diferenciar o que é genético, cognitivo e comportamental. Assim, o conhecimento mais aprofundado acerca do transtorno resulta em um programa de ensino mais condizente com a realidade da criança. Devem-se identificar, a princípio, as causas do problema da não aprendizagem, bem como fatores internos ou externos relacionados, para que se possa trabalhar de forma específica a dificuldade existente. Além disso, ressalta-se a importância de a criança ser estimulada na parte fonológica, algo que apresenta resultados bastante efetivos (Silva, 2018).

O processo de avaliação e diagnóstico das dificuldades específicas de leitura deve ser realizado por equipe interdisciplinar, envolvendo especialidades como neurologia, fonoaudiologia, psicologia, pedagogia ou psicopedagogia, além de considerar a percepção do professor que acompanha intimamente o processo de aprendizagem da criança. Uma intervenção bemsucedida depende de uma avaliação criteriosa e multidimensional desses fatores relacionados às dislexias de desenvolvimento.

É pertinente realizar novas pesquisas nesta temática, sugere-se assim, aprofundar os estudos buscando entender a percepção que os professores alfabetizadores tem da dislexia e o conhecimento que os mesmos tem sobre as estratégias que a Neuropsicologia oferece para auxiliar no processo de ensino-aprendizagem.

\section{Referências}

Alves, R.J. R. et al (2015). Teste para Identificação de Sinais de Dislexia: processo de construção. Estudos de psicologia, 32(3), $383-393$. 
Research, Society and Development, v. 10, n. 7, e21010716395, 2021

(CC BY 4.0) | ISSN 2525-3409 | DOI: http://dx.doi.org/10.33448/rsd-v10i7.16395

Blasi, H. F. (2006). Contribuições da psicolinguística ao estudo da dislexia. Universidade Federal de Santa Catarina (UFSC).

Capovilla, A. G. S. (2007). Contribuições da neuropsicologia cognitiva e da avaliação neuropsicológica à compreensão do funcionamento cognitivo humano. Cadernos de psicopedagogia, 6(11), 4-13.

Collares, C. A. L., \& Moysés, M. A. A. (2010). Preconceitos no cotidiano escolar: a medicalização do processo ensino-aprendizagem. Casa do Psicólogo, 193213.

Gonçalves, M. A. F. (2019). A dislexia no ensino fundamental. Revista Eletrônica Acervo Científico, 3(648).

Galvão, M. C. B., \& Ricartei, L. M. (2019). Revisão Sistemática da Literatura: conceituação, produção e publicação. Logeion: Filosofia da Informação, 6(1), 57-73.

Ianhez, M. E. \& Nico, M. Â. (2002). Nem sempre é o que parece: como enfrentar a dislexia e os fracassos escolares, Alegro.

International Dyslexia Association (IDA) (2020), Frequently Asked Questions https://dyslexiaida.org/frequently-asked-questions-2/

Kajihara, O. T. (1997). Avaliação das habilidades fonológicas de disléxicos do desenvolvimento. Universidade do Estado de São Paulo (USP).

Lira, N. R. F. et al (2020). Dislexia: a importância do diagnóstico para uma intervenção precisa. Research, Society and Development, 9(12).

Massi, G. \& Santana, A. P. O. (2011). A desconstrução do conceito de dislexia: conflito entre verdades. Padéia.

Medina, G. B. K., Souza, F. F., \& Guimaraes, S. R. K. (2018). Funç̃̃es executivas e leitura em crianças brasileiras com dislexia do desenvolvimento. Psicopedagogia, 35(107), 168-179.

Muszkat, M. \& Rizzutti, S. (2012). Educação \& Saúde: O professor e a dislexia. Cortez.

Neto, R. B. (2007). Neuropsicologia: o desenvolvimento da consciência, aprendizagem e transtornos. Universidade Estadual de Maringá (UEM).

Ribeiro, P. T. (2013). Fracasso escolar: reflexões sobre um problema que se repõe e possibilidades de enfrentamento. Universidade Metodista de Piracicaba (UNIMEP).

Rubino, R. (2008). Sobre o conceito de dislexia e seus efeitos no discurso social. Estilos da clínica, 13(24), 84-97.

Salles, J. F. \& Parente, M. A. M. P. (2006). Funções neuropsicológicas em crianças com dificuldades de leitura e escrita. Psicologia: Teoria e Pesquisa, 22(2), 153-162.

Salles, J. F. \& Parente, M. A. M. P. (2008). Variabilidade no desempenho em tarefas neuropsicológicas entre crianças de $2^{\mathrm{a}}$ série com dificuldades de leitura e escrita. Arquivos brasileiros de psicologia, 60(1), 32-44.

Salles, J. F.; Parente, M.A. M. P.; Machado, S. S. (2004). As dislexias de desenvolvimento: aspectos neuropsicológicos e cognitivos. Interações, 9(17), 109-132. Salles, J. F. \& Parente, M. A. M. P.(2006). Heterogeneidade nas estratégias de leitura/escrita em crianças com dificuldades de leitura e escrita. Psicologia, 37(1), 83-90.

Santos, M.T. M. \& Navas, A. L.G. P. (2002). Distúrbios de Leitura e Escrita: Teoria e Prática. Manole.

Signor, R. (2015). Dislexia: uma análise histórica e social. Revista Brasileira de Linguística Aplicada, 15(4), 971-999.

Silva, R. M. (2018). Dislexia na Aprendizagem. Revista Científica Multidisciplinar Núcleo do Conhecimento. 5(7), 107-138.

Sousa, A. M. O. P. \& Alves, R. R. N.(2017). A neurociência na formação dos educadores e sua contribuição no processo de aprendizagem. Psicopedagogia, $34(105), 320-331$. 